\title{
INFLUÊNCIA DA INFECÇÃO PELO VÍRUS DA ARTRITE ENCEFALITE CAPRINA NAS CARACTERÍSTICAS FÍSICO-QUÍMICAS E CELULARES DO LEITE DE CAPRINOS*
}

\author{
E.H. Birgel Junior ${ }^{1}$, V. Cestari ${ }^{1}$, R.M. Sampaio ${ }^{1}$, M.C.C.S.H. Lara ${ }^{2}$, \\ D.B. Birgel ${ }^{1}$, R.F.S. Raimondo ${ }^{1}$, F.B. Brandespin ${ }^{1}$, E.H. Birgel ${ }^{1}$
}

${ }^{1}$ Universidade deSão Paulo, Faculdade de Medicina Veterinária e Zootecnia, Departamento de Clínica Médica, Centro de Pesquisa e Diagnóstico de Enfermidades de Ruminantes, Av. Prof. Dr. Orlando Marques de Paiva, 87, CEP 05508-000, São Paulo, SP, Brasil. E-mail: ehbirgel@usp.br

\section{RESUMO}

Com o objetivo de avaliar a influência da infecção pelo Vírus da Artrite Encefalite Caprina (VAEC) nas características físico-químicas e celulares do leite foram colhidas 97 amostras de leite de cabras das raças Saanen e Pardo Alpina, sendo as amostras divididas em 3 grupos experimentais. O Grupo 1 foi composto de 36 amostras de leite de glândulas mamárias consideradas clinicamente sadias, sem crescimento bacteriano e provenientes de fêmeas reagentes ao antígeno do VAEC (soronegativas); o Grupo 2 foi composto de 49 amostras de leite de glândulas mamárias com consistência normal da mama (macia), sem crescimento bacteriano e provenientes de fêmeas reagentes ao antígeno do VAEC (soropositivas) e o Grupo 3 foi composto de 12 amostras de leite de glândulas mamárias com endurecimento difuso da mama (Mamite Indurativa), sem crescimento bacteriano e provenientes de fêmeas reagentes ao antígeno do VAEC (soropositivas). As amostras foram colhidas na sala de ordenha, imediatamente antes da ordenha do animal, sendo as seguintes características do leite determinadas: $\mathrm{pH}$, eletrocondutividade, cloretos, lactose, índice cloretos/ lactose, gordura, proteína, sólidos totais, contagem de células somáticas e exame microbiológico. Do total de 97 glândulas palpadas, observou-se que o endurecimento difuso da glândula mamária foi diagnosticado em 19,68\% das cabras infectadas pelo Vírus da Artrite Encefalite Caprina (VAEC). A análise dos resultados evidenciou a significativa influência da infecção pelo vírus da Artrite Encefalite Caprina (VAEC) na composição físico-química e celular do leite de caprinos, pois: a) os valores de eletrocondutividade, os teores de cloretos e a contagem de células somáticas foram maiores nas cabras infectadas pelo VAEC com ou sem sinais de endurecimento difuso da mama; $b$ ) os valores de lactose foram menores nas cabras infectadas pelo VAEC com ou sem sinais de endurecimento difuso da mama; c) os valores de proteína, gordura e sólidos totais foram menores somente no grupo de cabras infectadas pelo VAEC com sinais de endurecimento difuso da mama; c) os valores do pH não sofreram influência da infecção pelo VAEC.

PALAVRAS-CHAVE: Leite, características físico-químicas, contagem de células somáticas, caprinos, artrite encefalite caprina.

\section{ABSTRACT}

INFLUENCE OF INFECTION BY THECAPRINE ARTHRITIS-ENCEPHALITIS VIRUS (CAEV) ON THE PHYSICOCHEMICAL AND CELLULAR CHARACTERISTICS OF GOAT MILK. In order to assess the influence of an infection by the caprine arthritis-encephalitis virus (CAEV) on the physicochemical and cellular characteristics of the milk, 97 samples of milk were collected from goats of the Saanen and Oberhasli breeds. The samples were divided into 3 groups: Group 1 consisted of 36 samples collected from clinically healthy mammary glands, without bacterial growth, from females that were seronegative to the CAEV antigen; Group 2 with 49 samples collected from mammary glands with normal consistency (soft), without bacterial growth, from CAEV antigen seropositive animals; Group 3 was composed of 12 samples collected from hardened udders (indurative mastitis), without bacterial growth, from CAEV antigen seropositive animals. The samples were collected in the milking parlor immediately before the animals were milked. The $\mathrm{pH}$, electrical conductivity, chloride and lactose levels, chloride/lactose ratio, fat and

\footnotetext{
${ }^{2}$ Instituto Biológico, Centro de Pequisa Desenvolvimento de Sanidade Animal, São Paulo, SP Brasil.

*Projeto desenvolvido com apoio da Fundação de Amparo à Pesquisa do Estado de São Paulo - FAPESP 01/07461-6.
} 
protein content, total solids, somatic cell count and microbiologic profile were determined. It was found that $19.68 \%$ of the seropositive animals had a diffuse hardening of the udder. The data analysis demonstrates that there is significant influence of the infection by CAEV on the physicochemical and cellular composition of the milk, as: a) the electrical conductivity, chloride level and somatic cell count were higher in CAE positive animals, regardless of the hardening of the udder; $b$ ) the lactose content was lower in CAE positive animals, regardless of the hardening of the mammary gland; c) protein, fat and total solids contents were lower only in animals with hardened udders; d) the milk pH values were not altered by the infection with CAEV.

KEY WORDS: Milk, physicochemical characteristics, somatic cell count, goats, caprine arthritisencephalitis (CAE).

\section{INTRODUÇÃO}

A Artrite Encefalite Caprina é uma enfermidade infecciosa viral de distribuição cosmopolita, específica de caprinos e de evolução clínica lenta, progressiva e inexorável (CRAWFORD et al., 1980). Entre os animais clinicamente acometidos, a severidade dos sintomas podevariarmuito, masestaretrovirosedoscaprinostem sido associada a síndromes que incluem artrite e pneumonia em animais adultos e leucoencefalomielite em animais jovens (RoBINSON; ElLIS, 1986), podendo, também, ser responsável por uma mamite indurativa nas cabrasinfectadas (GoNZALES et al.,1987; KeNNEDY-STOSKOPF et al., 1985; Cheevers; McGuire, 1988; PerK, 1988).

Na glândula mamária de cabras infectadas descreveu-se o endurecimento gradativo com a presença de vários nódulos de consistência dura, que confluem para determinar um endurecimento difuso do parênquima mamário, resultando em assimetria das metades do úbere (GonZALES et al., 1987; KenNEDYStoskopf et al., 1985; Cheevers; McGuire 1988; Perk, 1988). No Brasil, o endurecimento gradativo da mama (mamite indurativa), em cabras infectadas pelo Vírus da Artrite Encefalite Caprina foi diagnosticado em 6,83 \% (17/249) das glândulas mamárias examinadas (LARA, 2002).

Segundo Sмiтн; Cutlip (1988), a média de produção de leite e de gordura de cabras infectadas pelo Vírus da Artrite Encefalite Caprina, verificada em um período de 305 dias de lactação, foi menor que a média alcançada pelas cabras não infectadas, sendo a produção de leite e de gordura nas cabras infectadas, respectivamente, $42,2 \mathrm{~kg}$ e $3,2 \mathrm{~kg}$, menores do que a observada nos animais não infectados. Tais observações foram confirmadas por BoHLAND; D' ANGELINO (2005) que, em pesquisa realizada nas condições brasileiras de manejo, verificaram que a produção leiteira nas cabras infectadas pelo Vírus da Artrite Encefalite Caprina era 21,5\% menor do que nos animais não infectados e que cabras infectadas apresentavam lactações mais curtas, sendo a sua duração, em média, 37 dias menor do que a observadas em animais não infectados.

A influência da infecção pelo Vírus da Artrite Encefalite Caprina na constituição celular do leite de caprinos foi, inicialmente, estudada porSmith;CUTLIP (1988), porém esses autores não puderam verificar a existência de diferenças no número de células somáticas no leite de cabras infectadas e sadias. Coube a RYAN et al. (1993) demonstrar que o número de células somáticas no leite de cabras reagentes ao antígeno do Vírus da Artrite Encefalite Caprina (entre $457 \times 10^{3}$ e $690 \times 10^{3}$ células somáticas $/ \mathrm{mL}$ ) era maior do que o número de células observadas no leite de glândulas mamárias de animais não reagentes ao antígeno do VAEC (entre $263 \times 10^{3}$ e $316 \times 10^{3}$ células somática/ $\mathrm{mL}$ ), sendo este fato confirmado, a seguir, por NORD; ÅDNøY (1997) e SANCHEZ et al. (2001).

Complementando as informações sobre as possíveis influências deste vírus na saúde da glândula mamária, NoRD; ÅDNøY (1997) verificaram que os valores de lactose, gordura e proteína não sofreram variações significativas que pudessem ser creditadas à infecção pelo Vírus da Artrite Encefalite Caprina.

A existência de poucas pesquisas procurando avaliar a influência da infecção pelo Vírus Artrite Encefalite Caprina nas características físico-químicas e celulares do leite de caprinos, bem como a ausência de informações sobre essa influência nos valores lácteos de $\mathrm{pH}$, eletrocondutividade e cloretos torna necessária a realização de estudos que elucidem a natureza dessa influência. Assim, a presente pesquisa foi delineada com o objetivo de avaliar a influência desta infecção viral nas características físico-químicas do leite pela determinação dos valores do potencial hidrogeniônico - $\mathrm{pH}$, eletrocondutividade, cloretos, lactose, gordura, proteína ecálculo doíndice cloretos/lactose e das características celulares do leite, por meio do California Mastitis Test - CMT e contagem de células somáticas, por citometria de fluxo, de caprinos, das raças Saanen e Pardo Alpina, criados no Estado de São Paulo.

\section{MATERIAL E MÉTODOS}

Para a realização da presente pesquisa foram colhidas 97 amostras de leite de cabras das raças Saanen e Pardo Alpina, sendo as amostras divididas em 3 grupos experimentais. OGrupo 1 foi composto de 
36 amostras de leite de glândulas mamárias consideradas clinicamente sadias, sem crescimento bacteriano e provenientes defêmeas não reagentes ao antígeno do Vírus da Artrite Encefalite Caprina (soronegativas); o Grupo 2 foi composto de 49 amostras de leite de glândulas mamárias com consistência normal da mama (macia), sem crescimento bacteriano e provenientes de fêmeas reagentes ao antígeno do Vírus da Artrite Encefalite Caprina (soropositivas) e o Grupo 3 foi composto de 12 amostras de leite de glândulas mamárias com endurecimento difuso da mama (mamite indurativa), sem crescimento bacteriano e provenientes de fêmeas reagentes ao antígeno do Vírus da Artrite Encefalite Caprina (soropositivas).

A identificação e seleção dos animais infectados pelo Vírus da Artrite Encefalite Caprina foi realizada por meio de avaliação sorológica para a detecção de anticorpos séricos precipitantes contra o vírus, sendo utilizado o teste de imunodifusão radial dupla em ágar gel (IDAG), empregando-se o antígeno do vírus Maedi/Visna GP135 (Meaditec 1000 Test Kit Central Veterinary Laboratory- New Haw, Reino Unido), segundo as recomendações de LARA (2002).

A seleção dos animais empregados nessa pesquisa baseada no exame clínico dos animais e no seu histórico (BIRGEL, 2004), não sendo utilizadas amostras provenientes de animais que apresentaram episódios recorrentes de mamite e que no momento da colheita apresentaram alterações das características macroscópicas do leite ou perceptíveis durante a palpação da mama.

As amostras utilizadas foram colhidas imediatamente antes da ordenha do animal. Procedeu-se, inicialmente, a anti-sepsia do orifício do teto, utilizandose algodão embebido em álcool $70 \%$, sendo desprezados os primeiros jatos de leite, para então realizar a colheita de cerca de $3 \mathrm{~mL}$ de leite, em frascos estéreis, os quais foram utilizados para o examemicrobiológico. Estas amostras foram acondicionadas em caixas de isopor, mantidas refrigeradas durante o transporte ao laboratório e congeladas a $-20^{\circ} \mathrm{C}$, no mesmo dia da colheita. Em seguida, foram colhidas amostras para determinação dos valores do $\mathrm{pH}$, cloretos e realização do California Mastitis Test(CMT) em frascos de plástico descontaminados de íons, acondicionados em caixas de isopor e mantidos refrigerados até o momento do processamento, sendo os exames concluídos antes de decorridas 24 h de conservação. Na seqüência, para a contagem do número de células somáticas e determinação dos valores de lactose, gordura, proteína e sólidos totais, foram colhidos cerca de $40 \mathrm{~mL}$ deleite em frascos de plástico contendo 2 pastilhas do conservante bromopol (2-bromo-2-nitro-propano-1,3diol), mantidos até o momento da realização dos testes refrigerados ou em temperatura ambiente, sendo as provas realizadas num prazo máximo de 7 dias após a colheita do leite. Para a determinação dos valores de eletrocondutividade do leite, as amostras de leite de cada glândula mamária forma colhidas e depositadas diretamente no receptáculo do equipamento utilizado, sendo o exame efetuado na sala de ordenha das propriedades.

A determinação do $\mathrm{pH}$ foi realizada utilizando-se um medidor de $\mathrm{pH}$ modelo M20 da Digimed e a determinação dos valores de eletrocondutividade foi efetuada, utilizando-se o aparelho Milku Mastitron. A determinaçãodos valores decloretos foirealizada por titulação coulométrica, utilizando-se o analisador de cloretos modelo 925 da Corning. A determinação dos valores de lactose, gordura, proteína e sólidos totais, foi realizada por radiação infravermelha utilizando-seo equipamento Bentley 2000 da Empresa Bentley Instruments Inc. O índicecloretos/lactose foi obtido mediante a divisão do valor decloretoexpressoemmg/dL pelovalor da lactose expresso em mg/dL e multiplicado por 100.

A avaliação do número de células somáticas do leite foi realizada de duas maneiras tradicionalmente aceitas em semiologia da glândula mamária e na tecnologia de produção higiênica de leite: o California Mastitis Test - CMT, avaliação qualitativa do número de células somáticas descrita porSCHALM;NOORLANDER (1957), e a contagem quantitativa do número de células somáticas doleite por citometria defluxo, utilizando-se o equipamento Somacount 500 da Empresa Bentley Instruments Inc e os resultados expressos em células somáticas $\times 10^{3} / \mathrm{mL}$.

Para a realização do exame microbiológico, as amostras de leite, após serem descongeladas, foram semeadas em meio deágar-sangue de carneiro e incubadas a $37^{\circ} \mathrm{C}$, sendo realizadas leituras com 24,48 e $72 \mathrm{~h}$ de incubação. Os exames bacterioscópicos foram realizados em lâminas coradas pelo Método deGram, sendo que os microganismos foram isolados e identificados por provas bioquímicas de acordo com as técnicas descritas por LENNETTE et al., (1985) e classificados deacordocomo Bergey's Manual ofSystematic Bacteriology (KRIEG; HolT, 1994).

Para calcular os valores da média aritmética e o desvio padrão, assim como avaliar a influência da infecção pelo vírus da Artrite Encefalite Caprina nas características físico-químicas e celulares do leite, utilizou-se o programa decomputadorSAS-Statistical Analysis System, aplicando-se, inicialmente, análise de variância, sendo, a seguir, utilizado, para comparação entre os pares de médias, o Teste de Duncan, com nível de $5 \%$ de significância conforme recomendaram BERQUÓ etal. (1981). Para a análise da contagem de células somáticas, que não apresentava distribuição normal, foi necessário, conforme recomendado por Ali; SHOOK (1980), a conversão dos dados em logaritmos na base 10 para que os testes estatísticos paramétricos pudessem ser utilizados. 


\section{RESULTADOS}

Na Figura 1 foram apresentados os resultados referentes a freqüência da ocorrência do endurecimento difuso da glândula mamária em caprinos nos quais não foram isolados agentes bacterianos no leite. Do total de 97 glândulas palpadas, observou-se que o endurecimento difuso da glândula mamária foi diagnosticado em 19,67\% (12/61) dos animais infectados pelo Vírus da Artrite Encefalite Caprina, sendo que, nos animais não reagentes aos antígenos do Vírus da Artrite Encefalite Caprina, a freqüência da ocorrência de endurecimento difuso da glândula mamária podia ser observado em 5,55\% (2/36) das mamas examinadas.

A análise dos resultados apresentados na Tabela1, para as características físico-químicas do leite de caprino demonstrou significativa influência da infecção pelo Vírus da Artrite Encefalite Caprina nos valores de eletrocondutividade, cloretos, lactose, proteína, gordura, sólidos totais e do índice de cloretos / lactose. Conforme pode ser visualizado nesta tabela, os valores do $\mathrm{pH}$ oscilaram entre 6,74 $\pm 0,08$ e 6,81 \pm 0,11 , sem que qualquer diferença estatística pudesse ser observada. Também, pode ser verificado que os valores obtidos para a eletrocondutividade no grupo composto por cabras infectadas pelo Vírus da Artrite Encefalite Caprina com consistência macia da mama $(7,33 \pm 0,60 \mathrm{mS} / \mathrm{cm})$, assim como no grupo

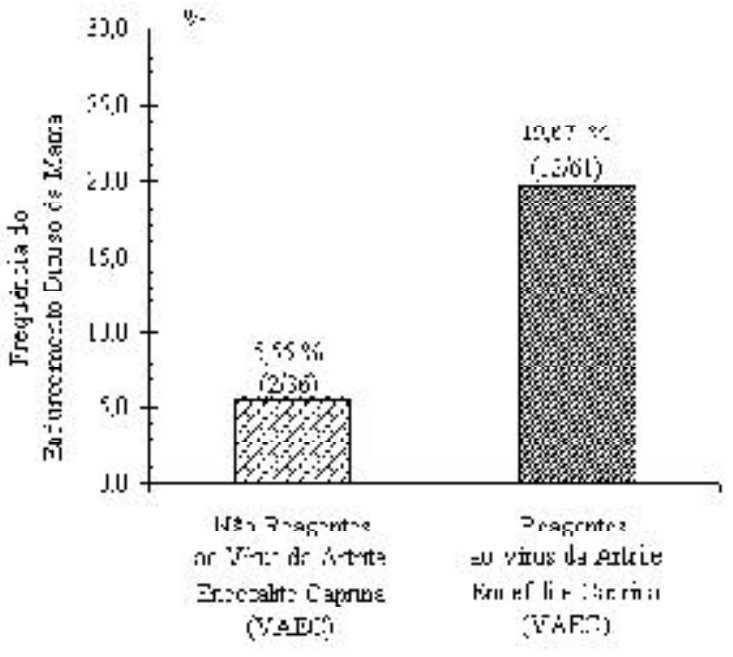

Fig. 1 - Freqüência da ocorrência do endurecimento difuso da glândula mamária de cabras, considerando-se somente os animais sem isolamento de agentes bacterianos no leite, distribuídos segundo a influência da infecção pelo vírus da artrite encefalite caprina (VAEC), criadas no Estado de São Paulo, São Paulo, 2006.

composto por cabras infectadas pelo Vírus da Artrite Encefalite Caprina com mamite indurativa $(7,26 \pm$ $0,51 \mathrm{mS} / \mathrm{cm}$ ), foram estatisticamente maiores dos que os valores obtidos nas cabras não reagentes ao antígeno do Vírus da Artrite Encefalite Caprina (6,60 $\pm 0,76 \mathrm{mS} / \mathrm{cm}$ ).

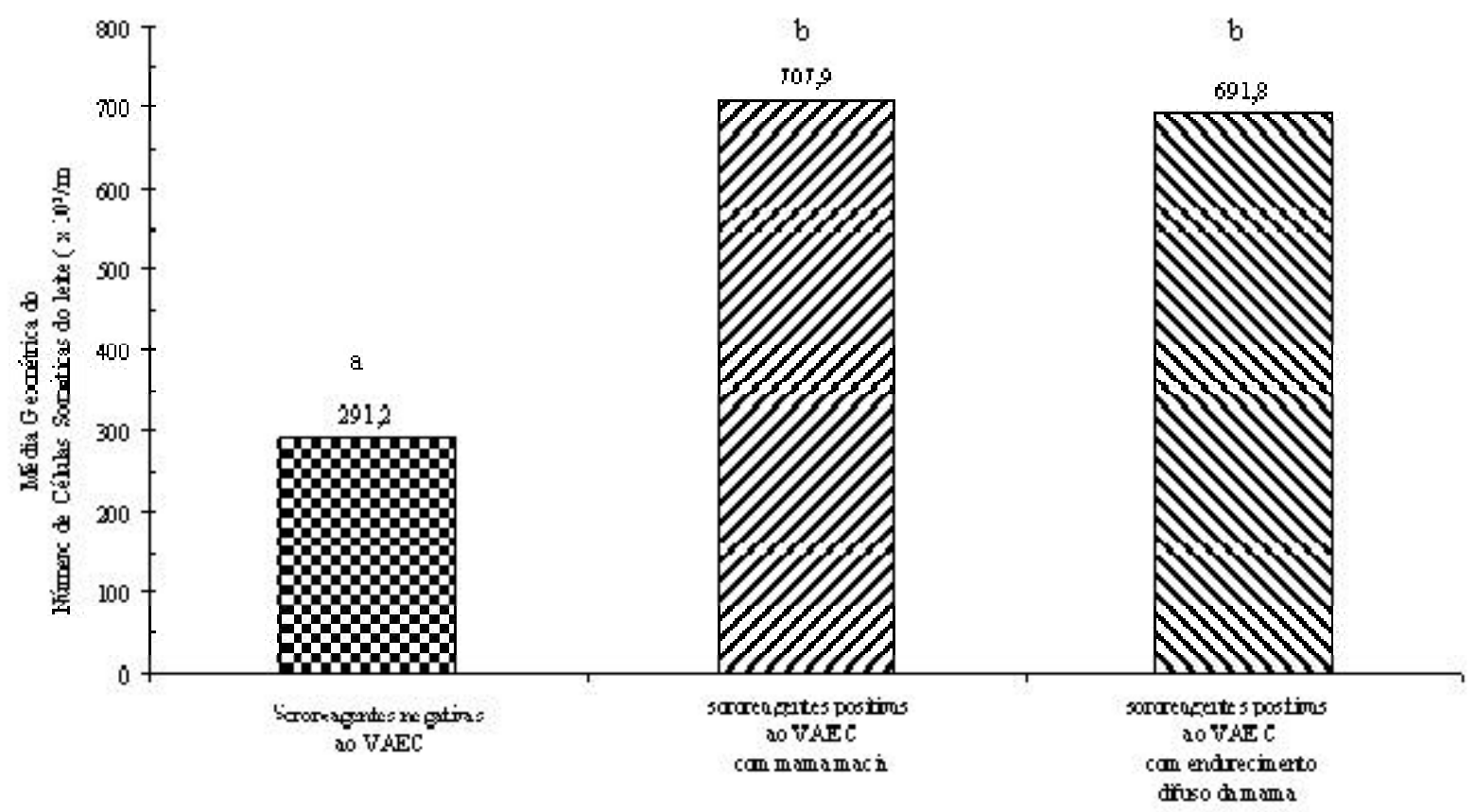

Fig. 2 - Influência da infecção pelo vírus da artrite encefalite caprina (VAEC) na contagem de células somaticas do leite de caprinos, criados no Estado de São Paulo, São Paulo, 2006. 
Tabela 1 - Média, desvio padrão e amplitude de variação das características físico-químicas (pH, eletrocondutividade, cloretos, lactose, índice de cloretos/lactose, proteína, gordura e sólidos totais) no leite de caprinos, distribuídos segundo a influência da infecção pelo Vírus da Artrite Encefalite Caprina (VAEC), criados no Estado de São Paulo. São Paulo, 2006.

\begin{tabular}{|c|c|c|c|}
\hline \multirow{5}{*}{ Variáveis } & \multicolumn{3}{|c|}{ Grupos experimentais } \\
\hline & Grupo 1: cabras sadias & $\begin{array}{l}\text { Grupo 2: mama com } \\
\text { consistência macia }\end{array}$ & $\begin{array}{l}\text { Grupo 3: mama } \\
\text { endurecimento difuso } \\
\text { (mamite indurativa) }\end{array}$ \\
\hline & não reagentes ao Vírus & reagentes ao Vírus & reagentes ao Vírus da \\
\hline & da Artrite Encefalite & da Artrite Encefalite & Artrite Encefalite \\
\hline & Caprina (VAEC) & Caprina (VAEC) & Caprina (VAEC) \\
\hline № de amostras & 36 & 49 & 12 \\
\hline \multirow[t]{2}{*}{$\overline{\mathrm{pH}}$} & $6,80 \pm 0,10 a$ & $6,81 \pm 0,11$ a & $6,74 \pm 0,08 \mathrm{a}$ \\
\hline & $(6,62-7,07)$ & $(6,64-7,13)$ & $(6,62-6,86)$ \\
\hline \multirow[t]{2}{*}{ Eletrocondutividade $(\mathrm{mS} / \mathrm{cm})$} & $6,60 \pm 0,76 a$ & $7,33 \pm 0,60 \mathrm{~b}$ & $7,26 \pm 0,51 b$ \\
\hline & $(5,20-7,70)$ & $(6,30-8,90)$ & $(6,80-8,80)$ \\
\hline Cloretos & $156,29 \pm 20,98 a$ & $175,08 \pm 20,38 b$ & $170,04 \pm 13,35 b$ \\
\hline$(\mathrm{mg} / \mathrm{dL})$ & $(110,05-191,70)$ & $(143,77-216,55)$ & $(150,16-193,47)$ \\
\hline Lactose & $4,53 \pm 0,18 \mathrm{a}$ & $4,30 \pm 0,25 b$ & $4,29 \pm 0,18 b$ \\
\hline$(\mathrm{g} / \mathrm{dL})$ & $(4,15-4,91)$ & $(3,67-4,65)$ & $(3,86-4,56)$ \\
\hline Índice cloretos/lactose & $3,46 \pm 0,57 a$ & $4,12 \pm 0,70 b$ & $3,97 \pm 0,45 b$ \\
\hline$(\%)$ & $(2,39-4,62)$ & $(3,20-5,88)$ & $(3,29-5,01)$ \\
\hline Proteína & $3,19 \pm 0,61 \mathrm{a}$ & $3,16 \pm 0,31$ a & $2,85 \pm 0,30 \mathrm{~b}$ \\
\hline$(\mathrm{g} / \mathrm{dL})$ & $(2,32-5,20)$ & $(2,55-4,21)$ & $(2,50-3,61)$ \\
\hline Gordura & $4,29 \pm 1,02 \mathrm{a}$ & $3,89 \pm 0,73 a, b$ & $3,69 \pm 0,68 b$ \\
\hline$(\mathrm{g} / \mathrm{dL})$ & $(2,64-6,82)$ & $(2,64-6,05)$ & $(2,14-4,50)$ \\
\hline Sólidos totais & $12,99 \pm 1,62 \mathrm{a}$ & $12,25 \pm 0,99 b$ & $11,70 \pm 0,96 \mathrm{~b}$ \\
\hline$(\mathrm{g} / \mathrm{dL})$ & $(10,34-17,82)$ & $(10,13-14,49)$ & $(10,00-13,72)$ \\
\hline
\end{tabular}

$\mathrm{a}, \mathrm{b}$ - letras diferentes, na mesma linha, significam diferença estatística significativa $(\mathrm{p}<0,05)$ - Teste de Duncan

Observou-se, ainda, na Tabela 1, que os valores obtidos para os teores de cloretos no grupo composto por cabras infectadas pelo Vírus da Artrite Encefalite Caprina com consistência macia da mama (175,08 \pm $20,38 \mathrm{mg} / \mathrm{dL}$ ), assim como no grupo composto por cabras infectadas pelo Vírus da Artrite Encefalite Caprina com mamite indurativa $(170,04 \pm 13,35 \mathrm{mg} /$ $\mathrm{dL}$ ), foram estatisticamente maiores do que os valores obtidos nas cabras não reagentes ao antígeno do Vírus da Artrite Encefalite Caprina (156,29 \pm 20,98 $\mathrm{mg} / \mathrm{dL}$ ). Também, observou-se que os valores obtidos para os teores de lactose no grupo composto por cabras infectadas pelo Vírus da Artrite Encefalite Caprina com consistência macia da mama $(4,30 \pm 0,25$ $\mathrm{g} / \mathrm{dL}$ ), assim como no grupo composto por cabras infectadas pelo Vírus da Artrite Encefalite Caprina com mamite indurativa $(4,29 \pm 0,18 \mathrm{~g} / \mathrm{dL})$, foram estatisticamente menores dos que os valores obtidos nas cabras não reagentes ao antígeno do Vírus da Artrite Encefalite Caprina $(4,53 \pm 0,18 \mathrm{~g} / \mathrm{dL})$. Da mesma forma, o índice de cloretos/lactose obtidos no grupo composto por cabras infectadas pelo Vírus da Artrite Encefalite Caprina com consistência macia da mama $(4,12 \pm 0,70 \%)$, assim como no grupo composto por cabras infectadas com mamite indurativa $(3,97 \pm$ $0,45 \%$ ) foram estatisticamente maiores do que os valores obtidos nas cabras não reagentes ao antígeno do Vírus da Artrite Encefalite Caprina (3,46 0 0,57\%).

Complementando a análise da Tabela 1, observouse que os valores obtidos para os teores de proteína no grupo composto por cabras infectadas pelo Vírus da Artrite Encefalite Caprina com mamite indurativa (2,85 $\pm 0,30 \mathrm{~g} / \mathrm{dL}$ ) foram estatisticamentemenores dos queos valoresobtidosnogrupocompostoporcabrasinfectadas pelo Vírus da Artrite Encefalite Caprina com consistência macia da mama $(3,16 \pm 0,31 \mathrm{~g} / \mathrm{dL})$ e no grupo compostonascabrasnãoreagentesaoantígenodoVírus da Artrite Encefalite Caprina (3,19 \pm 0,61 g/dL). Também foi verificado que os valores obtidos para os teores de gordura no grupo composto por cabras infectadas pelo Vírus da Artrite Encefalite Caprina com mamite indurativa $(3,69 \pm 0,68 \mathrm{~g} / \mathrm{dL})$ foram estatisticamente menores dos que os valores obtidos no grupo composto por cabras infectadas pelo Vírus da Artrite Encefalite Caprina com consistência macia da mama $(3,89 \pm 0,73$ $\mathrm{g} / \mathrm{dL}$ ) eno grupo composto nas cabras não reagentes ao 
Tabela 2-Freqüência da reação do California Mastitis Test (CMT) de cabras, distribuídos segundo a influência da infecção pelo Vírus da Artrite Encefalite Caprina (VAEC), criadas no Estado de São Paulo. São Paulo, 2006.

\begin{tabular}{|c|c|c|c|}
\hline $\begin{array}{l}\text { Reação do California } \\
\text { Mastitis Test (CMT) }\end{array}$ & $\begin{array}{l}\text { não reagentes ao Vírus } \\
\text { da Artrite Encefalite } \\
\text { Caprina (VAEC) }\end{array}$ & $\begin{array}{l}\text { Grupo 2: mama com } \\
\text { consistência macia } \\
\text { reagentes ao Vírus } \\
\text { da Artrite Encefalite } \\
\text { Caprina (VAEC) }\end{array}$ & $\begin{array}{l}\text { Grupo 3: mama com } \\
\text { endurecimento difuso } \\
\text { (mamite indurativa) } \\
\text { reagentes ao Vírus da } \\
\text { Artrite Encefalite } \\
\text { Caprina (VAEC) }\end{array}$ \\
\hline № de amostras & 36 & 49 & 12 \\
\hline-- & $83,32 \%$ a $(30 / 36)$ & $61,23 \%$ b (30/49) & $66,66 \%$ ab (8/12) \\
\hline$(+)-$ & $8,34 \%$ a $(3 / 36)$ & $18,37 \%$ a $(9 / 49)$ & $25,00 \%$ a $(3 / 12)$ \\
\hline+- & $2,78 \%$ a $(1 / 36)$ & $12,24 \%$ a $(6 / 49)$ & $8,34 \%$ a $(1 / 12)$ \\
\hline++ & $2,78 \%$ a $(1 / 36)$ & $8,16 \%$ a $(4 / 49)$ & $0,00 \%$ a $(0 / 12)$ \\
\hline+++ & $2,78 \%$ a $(1 / 36)$ & $0,00 \%$ a $(0 / 49)$ & $0,00 \%$ a $(0 / 12)$ \\
\hline
\end{tabular}

$a, b$ - letras diferentes, na mesma linha, significam diferença estatística significativa $(p<0,05)$ - teste de duas proporções.

antígeno do Vírus da Artrite Encefalite Caprina (4,29 \pm $1,02 \mathrm{~g} / \mathrm{dL}$ ). Da mesma forma, os valores obtidos para os teores de sólidos totais no grupo composto por cabras infectadas pelo Vírus da Artrite Encefalite Caprina com mamiteindurativa $(11,70 \pm 0,96 \mathrm{~g} / \mathrm{dL})$ foram estatisticamente menores dos que os valores obtidos no grupo composto por cabras infectadas pelo Vírus da Artrite Encefalite Caprina com consistência macia da mama $(12,25 \pm 0,99 \mathrm{~g} / \mathrm{dL})$ e no grupo composto nas cabras não reagentes ao antígeno do Vírus da Artrite Encefalite Caprina a $(12,99 \pm 1,62 \mathrm{~g} / \mathrm{dL})$.

Com relação aos resultados obtidos para o California Mastitis Test (CMT) verificou-se, conforme apresentado na Tabela 2, que a freqüência de reações negativas ao CMT, observada no grupo composto por cabras infectadas pelo Vírus da Artrite Encefalite Caprina com consistência macia da mama (61,23\%), foi menor do que a freqüência de reações negativas obtidas nas cabras não reagentes ao antígeno do Vírus da Artrite Encefalite Caprina (83,32\%). A aná- lise dos resultados obtidos para a freqüência de reações classificadas como traços ou $(+)-$; reações classificadas comolevemente positivo ou +- ; fracamente positivo ou ++- e fortemente positivo ou +++ não evidenciou diferenças estatísticas significantes entre os 3 grupos experimentais.

Conforme apresentado na Tabela 3 e na Figura 2, ao utilizar-se um método quantitativo para a Contagem das Células Somáticas (CCS) no leite de caprinos observou-se que os valores obtidos para o número de células somáticas no grupo composto por cabras infectadas pelo Vírus da Artrite Encefalite Caprina comconsistência macia da mama $\left(5,85 \pm 0,51 \log 10 / \mathrm{mL}\right.$ ou $707,9 \times 10^{3}$ células/mL), assim como no grupo composto porcabras infectadas pelo Vírus da Artrite Encefalite Caprina com mamite indurativa $\left(5,84 \pm 0,35 \log 10 / \mathrm{mL}\right.$ ou $691,8 \times 10^{3}$ células $/ \mathrm{mL}$ ), foramestatisticamentemaiores dosqueos valores obtidos nas cabras não reagentes ao antígeno do Vírus da Artrite Encefalite Caprina (5,44 £0,53 log 10/ $\mathrm{mL}$ ou $291,2 \times 10^{3}$ células/mL).

Tabela 3 - Média, desvio padrão e amplitude de variação da contagem das células somáticas - CCS no leite de caprino (expressos em $\log 10 / \mathrm{mL}$ ) distribuídos segundo a influência da infecção pelo vírus da artrite encefalite caprina (VAEC) ,criados no Estado de São Paulo. São Paulo, 2006.

\begin{tabular}{lccc}
\hline Variáveis & Grupo 1: cabras sadias & $\begin{array}{l}\text { Grupos experimentais } \\
\text { consistência macia }\end{array}$ & $\begin{array}{l}\text { Grupo 3: mama com } \\
\text { endurecimentodifuso } \\
\text { (mamite indurativa) } \\
\text { reagentes ao vírus da } \\
\text { artrite encefalite } \\
\text { caprina (VAEC) }\end{array}$ \\
\hline $\begin{array}{l}\text { não reagentes ao vírus } \\
\text { da artrite encefalite } \\
\text { caprina (VAEC) }\end{array}$ & $\begin{array}{l}\text { reagentes ao vírus da } \\
\text { artrite encefalite } \\
\text { caprina (VAEC) }\end{array}$ & 49 & 12 \\
\hline $\begin{array}{l}\text { Contagem de células } \\
\text { somáticas- CCS } \\
\text { log10/mL) }\end{array}$ & $5,44 \pm 0,53$ a & $5,85 \pm 0,51 \mathrm{~b}$ & $5,84 \pm 0,35 \mathrm{~b}$ \\
\hline
\end{tabular}

$\mathrm{a}, \mathrm{b}$ - letras diferentes significam diferença estatísitca significanta $(\mathrm{p}<0,05)$ - teste de Duncan 


\section{DISCUSSÃO E CONCLUSÕES}

As alterações de consistência da glândula caracterizadas pela presença de vários nódulos de consistência dura, que confluem podendo determinar um endurecimento difuso do parênquima mamário, foram similares às descritas por GonZALEs et al., (1987); KenNedy-Stoskopf et al., (1985); Cheevers; McGuire (1988); PERK (1988), sendo essa condição por nós denominada como mamite indurativa. Pelos resultados obtidos na presente pesquisa e por LARA (2002), a ocorrência da mamite indurativa em animais infectados pelo Vírus da Artrite Encefalite Caprina é freqüente no Brasil, sendo que esta forma clínica da enfermidade pode ser diagnosticada entre $6,83 \%$ e $19,67 \%$ dos animais infectados. O endurecimento difuso da mama, também, pode ser observado em animais não reagentes ao Vírus da Artrite Encefalite Caprina e, nesses casos, essa alteração da consistência da mama está relacionada à fibrose da glândula em decorrência a processos inflamatórios anteriores.

Apesar das recomendações da utilização de diversos testes e provas complementares, que avaliem a resposta inflamatória e/ ou a extensão da lesão decorrente a processos inflamatórios que acometem a glândula mamária, com exceção da pesquisa de NoRD; ÅDNøY (1997) que avaliaram os teores lácteos de gordura, lactose e proteína, não foram encontradas pesquisas que estudassem as características físico-químicas do leite em cabras infectadas pelo Vírus da Artrite Encefalite Caprina. Entre essas características físico-químicas são consideradas como fundamentais, no diagnóstico das mamites, a determinação dos valores do $\mathrm{pH}$, de eletrocondutividade e os teores de cloretos (BIRGEL, 2004). Demonstrou-se que os valores de eletrocondutividade e teores de cloretos eram maiores nos animais infectados pelo Vírus da Artrite Encefalite Caprina, enquanto os valores do $\mathrm{pH}$ não sofreram influência. Demonstrou-se, ainda, que valores de lactose foram menores nas cabras infectadas pelo Vírus da Artrite Encefalite Caprina com ou sem sinais de mamite indurativa, enquanto os valores de proteína, gordura e sólidos totais foram menores somente no grupo de cabras com mamite indurativa causada pelo Vírus da Artrite Encefalite Caprina. Discordou-se, portanto, de NoRD; ÅDNøY (1997) que não verificaram a existência de diferenças nas características do leite decaprinos infectados pelo Vírus da Artrite Encefalite Caprina.

Relativo a contagem de células somáticas, demonstrou-se que o seu número é maior nos caprinos infectados pelo Vírus da Artrite Encefalite Caprina independentemente deles apresentarem ou não mamite indurativa, estando essas observações em concordância com as referidas por RYAN et al. (1993), NORD; ÅDNøY (1997); SANCHEZet al. (2001) que, também, em amostras deleite, nas quais não havia crescimento bacteriano, verificaram que ao número de células somáticas nos animais infectados pelo VAEC era maior.

Afora os prejuízos econômicos na produção leiteira determinados pela infecção pelo Vírus da Artrite Encefalite Caprina, fato que fora bem caracterizado por SMith; CutLIP (1988) e por BoHLAND; D' ANGELINO (2005), demonstrou-se que, nas cabras com endurecimento difuso da mama em decorrência da infecção pelo Vírus a Artrite Encfalite Caprina (mamite indurativa), ocorria uma piora na qualidade do leite dos caprinos - representados pela redução dos teores de lactose, proteína, gordura e sólidos totais. Seguramente, essas alterações na qualidade do leite irão determinar uma redução do rendimento na produção de derivados lácteos acarretando prejuízos para produtores rurais e indústria de laticínios.

Apesar dos animais infectados pelo vírus sem endurecimento difuso da glândula mamária não apresentarem alterações nos valores de proteína, gordura e sólidos totais, observou-se a existência de significativas alterações nas demais características físico-químicas e celulares, sendo que o aumento dos valores de eletroconcutividade, dos teores decloretos, dacontagem de células somáticasedoíndicecloretos/ lactose, bem como a diminuição dos teores lácteos de lactose, são evidências que a mama é precocemente afetada por esta infecção. Pesquisas realizadas por KeNNEDYSTTOSKOPF et al.(1985) e LeRONDELLE etal. (1989) demonstraram que a mama é um dos órgãos-alvo do Vírus da Artrite Encefalite Caprina, sendo que, na dependência da evolução da enfermidade e do acometimento das mamas foram descritas, em exames histopatológicos, alterações como a ocorrência de infiltrações perivasculares e do próprio parênquima glandular por células mononucleares, linfoproliferação ehiperplasia dos folículos linfóides que podem evoluir para calcificação e necrose dos ácinos da glândula mamária (ZWAHLEN et al., 1983; Gonzales et al., 1987; Cheevers; McGuire, 1988; Perk, 1988). Estas observações sugerem que as cabras infectadas por este vírus apresentariam, também, um comprometimento do seu tecido mamário e explicariam as modificações na composição do leite encontradas por nós.

A infecção da mama pelo Vírus da Artrite Encefalite Caprina poderia, ainda, causar uma imunossupressão seletiva devido a alterações nas funções dos macrófagos (UUTILA, 1987), sendo relatado nos animais infectados pelo Vírus da Artrite Encefalite Caprina (VAEC) uma maior predisposição às infecções bacterianas (SMITH; CutLIP, 1988; RYAnetal.,1993). Apesar da possibilidade da infecção pelo VAEC ser um fator predisponente para a ocorrência da infecção bacteriana da glândula mamária, as alterações en- 
contradas na presente pesquisa não estão associadas a possíveis efeitos da existência de um processo de origem bacteriano, pois todas as cabras utilizadas não apresentavam isolamento bacteriano no exame microbiológico, sendo as alterações encontradas decorrentes da ação direta do vírus no tecido da glândula mamária.

\section{REFERÊNCIAS}

Alı, A. K.A.; SHоOк, G.E. An optimun transformation for somatic cell concentration in milk. Journal of Dairy Science, v.63, n.3,p.487-490, 1980.

Berquó, E.S.; SouZA, J.M.P.; Gotlieb S.L.D. Bioestatística. São Paulo: Editora Pedagógica e Universitária, 1980.352p.

BIRGEL, E.H. Semiologia da Glândula Mamária de Ruminantes. In: FertosA, F.L.F. (Ed.). Semiologia Veterinária: A arte do Diagnóstico: Editora Roca, São Paulo, 2004. p.353-398.

Bohland, E.; D'Angelino, J.L. Artrite Encefalite Caprina: avaliação dos aspectos produtivos e reprodutivos de animais infectados e não infectados. Brazilian Journal of Veterinary Research and Animal Science, v.42, n.2, p.81-88, 2005.

CheEvers, W.R.; McGuire, T.C. The Lentiviruses: MAEDI/ VISNA, caprine arthritis-encephalitis and equine infectious anemia. Advances in Virus Research. v.34, n.2, p.189-215, 1988.

Crawford, T.B., Adams D,.S.; Gheevers W.P.; Cork L.C. Chronic arthritis in goats caused by a retrovirus. Science, v.207, n.29, p.997-999, 1980.

Gonzales,L.;Gelabert,J.E.;Marlo, J.C.;OKariz, C.S. Caprine arthritis-encephalitis in the Basque country, Spain. Veterinary Record, v.120, n.5, p.102-109, 1987.

JutilA, M.A. Altered macrophage function and the pathogenesis of caprine arthritis-encephalitis. Dissertation Abstracts Internacional, n. 92, 311, 1987, apud Ryan et al.

Kennedy-Stoskopf, S.; Narayan, O.; Strandberg, J.D. The mammary gland as a target organ for infection with caprine arthritis-encephalitis virus. Journal Comparative Pathology, v. 95, p. 609-617, 1985.

Lara, M.C.C.S.H. Artrite Encefalite dos Caprinos - aspectos clínicose epidemiológicos.2002.247p. Tese(Doutorado). Faculdade de Medicina Veterinária e Zootecnia, Universidade de São Paulo. São Paulo, 2002.
Lennete, E H.; Balows, A.; Hausler, W.J. Manual of clinical microbiology. Washington: American Society of Microbiology, 1985. 970p.

LeRONDELLE, C.; F LeURY, C.; V IALARD, J. The mammary gland: a target organ for infection with caprine arthritisencephalitis virus. Annales de Recherches Vétérinaires, v.20, n.1/2, p.57-63, 1989.

NORD K.; $\AA$ DNøY, T. Effects of infection by caprine arthritisencephalitis virus on milk production of goats. Journal of Dairy Science, v.80, n.10, p.2391-2397, 1997.

Perk. K. Ungulate lentiviruses: Pathogenesis and relationship to AIDS. Advances in Veterinary Science and Comparative Medicine, v.32, p97-127, 1988.

RoBINSON, W.F.; ElLIS, T.M. Caprine arthritis-encephalitis virus infection: from recognition to eradication. Australian Veterinary Journal, v.63, n.8, p.237-241,1986.

Ryan D.P.; Greenwood P.L.; Nichols P.J. Effect of caprine arthritis-encephalitis virus infection on milk cell count and N-acetyl-beta-glucosaminidase activity in dairy goats. Journal of Dairy Research, v.60, n.3, p.299306, 1993.

Sanchez, A.; Contreras, A.; Corrales, J.C.; Marco, J.C. Relationships between infection with caprine arthritis encephalitis virus, intramammary bacterial infection and somatic cell counts in dairy goats. Veterinary Record, v.148, n.23, p.711-714, 2001.

Schalm, O.W.; Noorlander, B.S. Experiments and observations leading to developmente of the california mastitis test. Journal American Veterinary Medical Association, v.30, n.5, p.199-204, 1957.

SмIтH, M.C.; CutLIP, R. Effects on infection with caprine arthritis-encephalitis virus on milk production in goats. Journal American Veterinary Medical Association, v.193, n.1, p.63-67, 1988.

Vanlandingham, A.H.; Chas, E.; Weakley, J.R. Moore, E.N.; Henderson, H.O.; Mastitis,. I. Relationship of the development of mastitis to changes in the chlorine, lactose and casein number of Milk. Journal of Dairy Science, v.24, n.1, p.383-398, 1941.

ZWAhlen, M.; Aeschbacher,M.;B ALCER, T.;StUCKI,M.;WYderWAlther, M.; W eISS, M.;STECK, F. Lentivirusinfektionen bei Ziegen mit Carpitis und intersitieller Mastitis. Schweizeriche Archiv für Tierheilkunde, v.125, n.5, p.281299, 1983.

Recebido em 10/8/06

Aceito em 1/8/07 